\title{
HET MIDDELBAAR ONDERWIJS VOOR MEISJES, BESCHOUWD IN VERBAND MET DE VOLKSHUISHOUDKUNDE.
}

\author{
(Ingezonden.)
}

Het is inderdaad opmerkelijk, dat trots den grooten vooruitgang van beschaving, volksontwikkeling en ook van volkshuishoudkunde in onze eeuw, men eerst in de laatste twintig a dertig jaren meer algemeen begonnen is over de ware maatschappelijke zending der vrouw, over de voor haar bestemde plaats in de samenleving, over hare eigenlijke levensbestemming, ernstig na te denken.

Toch blijft ten opzichte van dit alles de meening nog zeer verdeeld. Voor sommigen is de vrouw nog immer, geheel of althans hoofdzakelijk, bestemd, om den man te behagen, om hem veelzijdig zingenot te verschaffen; om eene rol te spelen in het bruisende-leven van onze kunstenaarswereld; om te zijn en te blijven "de bloem der waereld," maar dan ook enkel eene bloem, die slechts 't genot streelt, zonder eenig werkelijk en hooger nut te bezitten.

Anderen, die gewoon zijn personen en zaken met koeler gemoedsaandoening, en bij voorkeur van de nuttige en practische zijde gade te slaan, verlangen in den grooten maatschappelijken strijd ook van de vrouw bewijzen voor haar volkshuishoudkundig recht van bestaan, en kennen haar eene zelfstandige, voor de maatschappij onmisbare levenstaak toe, eene taak, waarvan de vervulling haar niet enkel beminnelijk en aantrekkelijk, maar ook nuttig en van degelijke onbetwistbare en door den tijd niet zoo gemakkelijk aantastbare waarde kan maken. Niet enkel behagen - dat zóo kort van duur en niet in ieders macht is! - maar ook arbeiden naar de juiste mate van haar bijzonder arbeidsvermogen is, volgens hen, de meer verheffende, edele roeping der vrouw van onzen tijd.

En dezen haren zelfstandigen en bijzonderen werkkring wijzen zij haar aan in het gezin. In het leven in gezinnen vervit zij, 
hetzij als gehuwde vrouw of weduwe, hetzij als ongehuwde, bloedverwant of eenvoudig vreemde huishoudster, eene belangrijke volkshuishoudkundige rol. Dat leven toch, het raderwerk van de geheele maatschappelijke machine, is een der voorname, doch meest verzuimde en verwaarloosde factoren van productie, consumptie en reproductie, en de vrouw heeft wel niet direct voor de voorlbrenging der waurde, maar toch wel voor de verdeeling van het genot en zelfs, met den man gemeenschappelijk, ook voor de vorming van kapitaal uit de juiste verhouding van het genot tot de productie der waarde te zorgen. Hierin alleen of althans hoofdzakelijk moet men, volgens sommige der tegenwoordige economisten, de hooge, tegelijk huishoudelijke en door hare huishoudelijke macht ook zedelijke waarde der vrouw zoeken. De kern van hare eigenlijke levenstaak ligt in het gezin, in de huishouding, in hare betrekking tot de consumptie in het familieleven.

Zelfs bloot uit een economisch oogpunt beschouwd, en in verband gebracht met den nationalen rijkdom en het wereldkapitaal, is de invloed der vrouw in het gezin beduidender dan velen wel denken. Zoo heeft b. v. Lorenz von Stein, door uitvoerige berekeningen, eens aangetoond hoe 0 . a. ééne enkele van hare huishoudkundige eigenschappen, met name ordelijkheid, het zorgvuldig schoonhouden, vernieuwen en verstellen van kleeding, huisraad enz. een volk millioenen schats rijker, en het gemis daarvan bij de vrouw, even zoo vele millioenen armer kan maken. Hij neemt bij deze berekeningen aan - en ik geloof niet, dat hij ernstige tegenspraak op dit punt zal aantreffen - dat alleen met betrekking tot de kleeding ieder stuk door orde, zindelijkheid en verstellen met naald en schaar het tien dagen in plaats van negen, tien jaren in plaats van negen uithouden en dienst doen kan. Op 't allerzuinigst berekend, bespaart zij dan alleen door haar behoudenden arbeid jaarlijks in elk geval $10 \mathrm{pCt}$. van dat gedeelte der aan hare zorg toevertrouwde roerende goederen. Dit zal voor ieder huisgezin dooreen gerekend jaarlijks gemiddeld toch wel vijf gulden uitmaken, welke de vrouw wel niet vourtbrengl, doch, uirl verloren laat gaan. Volgens de jongste opgaven beliep het getal huisgezinnen in ons land 748,732 ; zoodat de nederlandsche vrouwen daardoor alleen jaarlijks $f 3,743.660$ besparen kunnen, die de mus niet besparen kan.

En gesteld nu dat door gebrek aan kennis, althans aan voldoende en algemeen verspreide kennis van de nuttige vrouwelijke handwerken, en in het algemeen door gebrek an eene opleiding 
der vrouwen in huishoudkundigen geost, in de nederlandsche huisgezinnen, dooreen gerekend, vijf gulden waarde aan kleeding in plaats van besparrd, verknoist worden, dan hebben we een jaarlijksch verlies van ruim zeven milliorn, in plaats van een winst van drie en een half.

Indien door slordigheid en gebrek aan huishoudkundige kennis, slechts dooreen gerekend, een dubbeltje per dag in de huisgezinnen aan verloren boter, ongenuttigde aardappelen, niet noodige suiker, heel of half bedorven bouillon, soep, vleesch, melk, noodeloos vuur of licht, door de vrouw verkwist wordt, veroorzaakt die schijnbaar onbeduidende verkwisting in de ruim zeven maal honderd duizend nederlandsche huisgezinnen, jaarlijks een verlies aan nationaal vermogen van ruim zeven en twintig millioen gulden.

Dat zijn nu slechts een paar voorbeelden ter bevestiging der stelling, dat de vrouw, als bestuurderes der huishouding, eene hoogst gewichtige volkshuishoudkundige beteekenis bezit. Men zou nog honderde bewijzen in dien geest kunnen bijbrengen.

Doch ook de gevolgen die uit gebrek aan huishoudkundige kennis en helder inzicht in hare volkshuishoudkundige roeping voor de vrouw zelve ontstaan, mag men niet uit het oog verliezen. Slechte huishoudsters zijn in den regel ook ongelukkige vrouwen, die hare onkunde met pijnlijk verdriet en niet zelden met geheel of gedeeltelijk verlies van de liefde, althans de achting van hare echtgenooten moeten betalen. In eene huishouding, waarvan het beheer aan eene onbedrevene, niet in huishoudkundigen geest opgeleide vrouw is toevertrouwd, beginnen al spoedig de uitgaven de inkomsten te overschrijden en later veelal het kapitaal zelf te verteren. Eerst ontstaan, ten gevolge van onkunde en gebrek aan kennis van huishoudbestuurkunde, de kleine schulden; die kleine schulden hoopen zich op, worden posten van uitgaven, die niet meer uit de gewone inkomsten kunnen bestreden worden. De man moet geven, telkens meer geven, vaak zelfs een gedeelte van zijn bedrịfskapitaal of van sommen, die hij voor een ander doel bestemd had. De ontevredenheid begint aan weêrskanten : bij de vrouw, die steeds geld te kort komt en hare eischen ten laatste door haren man ziet afgewezen; bij den man, die inziet dat men op den duur niet enkel met eene mooie en jonge vrouw huis kan houden en zich nu bitter teleurgesteld, ontmoedigd en tot uitbreiding van zijn gezag over zijn lief, mooi, maar onkundig, maar verkwistend vrouwtje aangedrongen gevoelt. Er is nu eene der gevaarlijkste zedelijke ziekten in het gezin binnen geslopen. ${ }_{n}$ Cijfers zijn onverbiddelijk," - zegt von Stein, waaraan wij deze ge- 
dachtèn ontleenen; - zij leggen hunne koude hand op geluk en „liefde, en de eerste traan valt op de eerste..... onbetaalde ${ }_{n}$ rekening. Welk een proza! En toch, welk een vreeselijke ernst „in dit proza! Kent gij het? Gij behoedt uwe kinderen voor elke "ziekte, voor elke verkoudheid; gij begiet uwe bloemen en voedert „uwe vogels - en gij toont uwe dochter niet aan, hoe het ge"vaarlijkste gift van al het huwelijksgeluk langzaam en ongemerkt „in uw huis kan woekeren, totdat het in merg en nieren dringt, "en den huishoudelijken dood, den dood der liefde - en hoe dik"wijls den dood van het leven - na zich sleept."

$\mathrm{Z}_{\mathrm{ij}}$ dus, die verlangen dat in de opleiding der nederlandsche vrouw ook het aanleeren van theoretische en zoo mogelijk ook practische huishoudkunde worde ingevoerd, handelen inderdaad zoo. gedachteloos en onverstandig niet, als hun door hunne tegensprekers ten laste wordt gelegd, on de vraag rijst zelfs: of hunne bestrijders, bij het aanprijzen van eene andere opleiding, die geheel of hoofdzakelijk slechts een letterkundig karakter bezit, en bijna uitsluitend het aanleeren van talen, wiskunde, geschiedenis en aardrijkskunde op den voorgrond stelt, wel van een even verdedigbaar en rationeel stelsel nitgaan?

Het streven van die voorstanders der huishoudkunde mag ook zeker niet gerangschikt worden onder die „overdrijving" waarvan de heer Steijn Parvé (*) onlangs in dit tijdschrift gewaagde, eene overdrijving $n$ die wil, dat kinderen op school alles zullen leeren, "wat hun later als volwassen menschen misschien zal kunnen te pas „komen." Die voorstanders toch verlangen volstrekt niet, dat onze meisjes alles zullen leeren wat haar misschien, maar toch wel iels van hetgeen haar stellig in later leven te pas zal komen. En dat nu de meeste vrouwen, hetzij zij huwen of ongehuwd blijven, geheel of gedeeltelijk met het bestuur van een gezin, de opvoeding en verpleging van kinderen zullen belast worden, is minstens veel waarschijnlijker, dan dat allen, dan dat de meerderheid, dan dat zelfs vele van haar later tijd on lust zullen hebben om, behalve eenige romans en tijdschriften over mode, degelijke zware wetenschappelijke literatuur of de meesterstukken in de verschillende vroeger aangeleerde leervakken in 't oorspronkelijke te lezen.

Ik zeg dit alles niet om het nut van het aanleeren van zelfs zeer grondige kennis van talen in de $H$. B. S. voor meisjes te betwisten of de waarde van zulk eene kennis ook voor vrouwen tè

$\left(^{*}\right)$ Vgl. Economist Febr. 1877, blz, 169 , 
verkleinen. Want ook mijn gevoelen is, dat in deze of dergelijke scholen werkelijk grondig, degelijk en vollediy taal- en ander onderwijs moet worden gegeven. Ik haal dit alles slechts aan om onzen tegenstanders wat meer eerbied voor huishoudkunde in te boezemen en te voorkomen, dat zij deze nieuwe wetenschap als eene indringster of eene conbeduidende nieuweling beschouwen.

$\mathrm{Nu}$ werpt men ons ook tegen, dat het getal van hen, die invoering der huishoudkunde in de opleiding der vrouw verlangen, uiterst klein is. Dr. Stejn Parvé doet het zelfs voorkomen, alsof, behalve Multapatior, nog slechts "Constant" on de Redactie van de Tijdspiegel zoo iets verlangen. Maar de heer Steijn Parvé staat bij mij te hoog als wetenschappelijk man aangeschreven, dan dat ik denken kan dat hij - gesteld zelfs dat wij werkelijk zoo gering in getal waren - om elie reden ons stelsel veroordeelen of geen ernstig en gezet onderzoek waard zou achten. Groote en goede gedachten, zelfs dezulken, die wel eens eene gansche omwenteling in de geleerde wereld en de publieke opinie hebben gebracht, gingen gewoonlijk slechts van weinigen, soms zelfs van één enkelen denker en werker uit; werden meestal aanvankelijk uitgelachen en hartstochtelijk bestreden en eindigden met zich van lieverlede te ontvouwen, dieper en dieper in te wortelen en ten laatste oudere stelsels en opvattingen te verdringen.

Maar bovendien berust de voorstelling, alsof het getal dergenen, die de wetenschappelijke opleiding der vrouw meer direct in verband willen gebracht hebben met hare volkshuishoudkundige bestemming in de maatschappij, zoo uiterst klein is, bepaald op onkunde. In Duitschland, Zwitserland en Engeland toch vindt dit stelsel reeds algemeene toepassing. Ik heb dit in mijne brochure uit uitvoerige bescheiden aangetoond. Zelfs in Nederland - waar men, zelfs met de beste hervormingen, steeds achter andere volken aankomt - beginnen zich nu reeds sporen van verandering van zienswijze te vertoonen. Zoo werd bij de oprichting van de H. B.S. voor meisjes te Leeuwarden door 140 Friesche geneesheeren aan den gemeenteraad van die stad aangevraagd om onder de aldaar te onderwijzen leervakken op te nemen: gezondheidsleer, tourenkennis, kuishoudkunde on opvoedkunde. Behalve te Leeuwarden door den inspecteur Dr. Ali Cohen, wordt nu reeds de gezondheidsleer aan meisjes gedoceerd te Arnhem door Dr. Th. Warhman, to Groningen door Prof. Huizinga, en voorts door anderen te Dordrecht, Utrecht enz. Voedingsleer en ziel- en opvoedkunde worden reeds to Arnhem aan meisjes der H. B. S, onderwezen. 
Laten derhalve onze bestrijders betere argumenten om ons stelsel aan te vallen opzoeken, dan op ons klein getal te wijzen. Kleine getallen kunnen groote, en groote ook kleine worden. Dat is een der meest voorkomende verschijnselen in de republiek der gedachten der menschheid.

Iets minder pover figuur als bestrijdingsmiddel maakt de door onze tegensprekers aangevoerde voorstelling, dat huishoudkundige kennis - gesteld dan eens dat zij werkelijk nuttig ware - zóó gemakkelijk verkregen wordt, dat reeds de algemeene wetenschappelijke ontwikkeling, die H. B. S. voor meisjes aan hare bezoeksters bezorgt, elk meisje daarin voldoende bedreven makt en zij bovendien de huishoudkunde voldoende van hare moeders kunnen leeren. Dr. Steijn Parvé haalt tegen ons de getuigenis in dien geest aan van eenige dames Directrices van H. B. S. Maar of nu juist deze ongehuwde dames, die het grootste gedeelte van haar leven aan de studie moesten wijden, wel zeer vertrouwbare vraagbaken in deze materie zijn, laat ik liefst aan het oordeel over van hoofden van gezinnen, bejaarde en gehuwde vrouwen en moeders. Een vrouw van talent, die zich onder 't pseudoniem "Thecla" verbergt, denkt er geheel anders over dan bovengenoemde directrices. Sprekende over de noodzakelijkheid om oene bijzondere klasse tot het aanleeren van huishoudkunde voor meisjes te openen, zegt zij o. a.: "Waarom deze klasse vraagt men, daar „toch de moeders hare dochters het huishouden kunnen leeren? ${ }_{n}$ Mijne wedervraag luidt: Hoevele moeders kwijten zich van dezen nplicht? Hoe doen zij het? En hoe past de practijk van vroeger met „al hare overgeleverde vooroordeelen, baker- en keukenmeids"legenden en wat niet al, op de hedendaagsche huishouding, de "hodendaagsche kennis, de hedendaagsche behoeften?.... Hoe „vele vrouwen uit den gegoeden stand zoo wel als onder de minste "burgers, weten wat in kleeding, roeding en behandeling goed of "slecht voor hare kinderen is?"

In Duitschland en Zwitserland, waar 't gebruikelijk is, dat de meisjes eenigen tijd tot amileeren der huishouding in hôtels of naar bekwame huismoeders worden gezonden; waar bijna iedere vrouw, tot welken maatschappelijken stand zij ook behoort, zich persoonlijk het beheer der huishouding aantrekt, kan men van de huishoudkundige opleiding der meisjes door hare eigene moeders het beste verwachten. Maar dat zelfde kan men niet doen in landen, waar de vrouw uit de middenklasse des rolks een groot gedeelte van den arbeid des mans, in winkel en magazijn op zich 
neemt; waar de vrouw uit de hoogere klasse - in lịnrechte tegenoverstelling van de Duitsche en Zwitsersche vrouw - in 't bestuur van eene huishouding iets vernederends en beneden hare waardigheid ziet en alles aan hare dienstboden overlaat; waar dan ook in alle huisgezinnen in den regel aan de keuken weinig zorg wordt besteed, enz.

En kan nu soms ook die algemeene wetenschappelijke kennis die aan de H. B. S. voor meisjes verkregen wordt, 't gebrek aan kennis van huishoudkunde aanvullen $P$ Kan de laatstgenoemde kennis voldoende door de eerste verkregen worden?

Ik aarzel niet daarop neen te antwoorden.

De taak der vrouw in het gezin vormt, mijns inziens, een bepaald beroep; een beroep zoo goed als dat van den landbouwer, den architect, den koopman of industrieel. In deze opvatting sta ik niet alleen; ik zie haar bevestigd door ernstige denkers, zooals o. a. een Smiles, een von Steijn en anderen.

Een beroep nu leert men niet aan dan door er speciale studie van te maken en er eene bijzondere opleiding in te bekomen. Geen verstandig vader zal b. v. zijn zoon, bij het verlaten der H. B. S., aan 't hoofd eener landhoeve plaatsen. Hij zendt hem, alvorens dit te doen, in of buiten ons land naar eene landbouwschool, waar de jongen, door ' $t$ aanleeren van Landhuisbestuurkunde, Landhuishoudelijk boekhouden, Landbouw-, Schei- en Werktuigkunde, Voedingsleer, toegepaste plantenkunde enz. eene bepralde beroepsopleiding erlangt.

Evenmin mogen of kunnen wij van onze H. B. S. voor meisjes, zoo lang aldaar ook de gelegenheid tot het ontvangen van speciaal onderwijs in Huishoudkunde en de daaraan verwante leervakken niet bestaat, verwachten, dat zij onze dochters voor haar beroep zullen bekwamen.

En let nu wel op, dat voor het meisje de H. B. S. de hoogste, maar ook tevens de laatste school is, die zij bezoekt. Zij kan nu hoogstens misschien nog wel bij of van hare moeder eenige bloot werktuigelijke handgrepen en huiselijke bezigheden aanleeren, zoo als b. v. stijven, strijken, vleesch braden en een podding bereiden, maar de grondige, wetenschappelijke kennis van haar beroep leert zij niet meer. En toch geeft juist deze alleen aan eene in de huishoudkunde en hare aanverwante vakken goed onderwezen vrouw dien ernst, die waardigheid en vooral die vastheid in denken, oordeelen en handelen, die een onbedreven, slecht opgeleid rrouwtje ten eenemale mist. Voor de in haar beroep 
wetenschappelijk goed onderwezen vrouw worden al de, zelfs schijnbaar onbeduidendste verrichtingen in keuken, kelder, provisiekamer, waschhuis, zieken- en kinderkamer, zaken van werkelijk groot aanbelang; hare op haar beroep geheel in toepassing gebrachte wetenschappelijke kennis omgeeft haar bij al ha.e bezigheden in het gezin met een aangenamen, verkwikkenden, steeds opbeurenden wetenschappelijken dampkring, zoo aantrekkelijk voor elk denkend mensch. Alleen zulk eene vrouw erlangt de zelfbewustheid van met inzicht, volgens zekere positieve, rationeele, door de wetenschap geijkte regelen, en niet naar een sleur van bloote voorschriften, waarvan het hoe en het wockarom onbekend en onbewezen zijn, te arbeiden. Zij alleen kan van al haar doen en laten in haar bestuur aan zich zelve en asn anderen rekenschap geven, zij alleen kan gerust wijdstrekkende gevolgtrekkingen maken; zij alleen is in staat aan dat gedeelte der hervorming van het maatschappelijk leven, dat men het leven in gezinnen noemt, te kunnen arbeiden.

De groote vraag is nu echter maar: welke leervakken rangschikken wij, voorstanders der Huishoudkunde, onder de wetenschap en hoe moet het onderwijs daarin ingericht worden zal het werkelijk doel treffen?

Laat ons eerst een blik op de leerwijze, en eerst daarna op de leersiof slaan.

Even als bij landhuishoudkunde treedt ook hier de groote vraag op: kan huishoudkundig onderwijs uitsluitend thtoretisch zijn? Met andere woorden: moet het meisje, dat de wetenschappelijke zijde van haar beroep leert, ook niet vertrouwd gemaakt worden niet de practijk?

Ik zou geneigd zijn, hierop onvoorwaardelijk een bevestigend antwoord te geven, ware 't niet, dat mij de schier onoverkomelijke bezwaren, ja zelfs het bepaald ook door mij ongewenschte voor den geest stond om aan onze H. B. S. voor meisjes zelve ook inrichtingen b. v. voor het bereiden van spijzen, het bezorgen van de wasch enz. te verbinden.

Maar dat alles behoeft ook volstrekt niet. In groote steden bestaat voor de meisjes der H. B. S., die in Huishoudkunde opgeleid zouden worden, nu reeds menige zeer geschikte gelegenheid om, onder toezicht en leiding van eene van hare leeraressen in dat vak zich ook in de practijk te bekwamen. Zoo b. v. kon zij in eene bestaande of op te richten crếche de eerste verpleging en opjvoeding, in eene goede bewaarschool de eerste intellectueele ontwikkeling van kinderen, in het gasthuis de verpleging van 
zièken, in hôtels, gaarkeukens of groote gestichten het koken, in weeshuizen de huiselijke verrichtingen en zóó elders het overige gedurende eenige uren in de week gaan aanleeren. Doch altijd zou de theorie de practijk vooraf moeten gaan; de leerling zou niets moeten verrichten dan om werkelijk te leeren en dus onder toezicht moeten blijven van deskundigen en niet van ongeletterde, niet in huishoudkunde bedreven vrouwen. Wellicht ware, geheel afgescheiden van de H. B. S., ter aanvulling van het geleorde eene bijzondere Huishoudkundige school wenschelijk, doch niet in den geest der door den oud-hoogleeraar J. Jongeneel gewenschte "Huishoudschool".

En nu de leerstof der Huishoudkunde. Inderdaad, 't is uiterst moeielijk de grenzen van zulk eene jeugdige, pas opgetreden wetenschap met juistheid te bepalen. Het gaat met haar zoo als 't met de wetenschappelijke Landhuishoudkunde bij dezer eerste invoering ging: de een zocht het zwaartepunt van die wetenschap in dit, de ander weder in dat vak; de een zag er uitsluitend landbouw in, de ander beschouwde en behandelde haar als eene vereeniging van zeer verschillende, doch geheel op den landbouw loegepasle leervakken.

De laatste opvatting begint, met betrekking tot de Huishoudkunde, den boventoon te erlangen en zij is, mijns bedunkens, de ware.

Als proeve van bewerking in dezen geest zij het mij vergund - daar zelfs ook Dr. Steijn Parvé verklaart, eigenlijk niet te weten wat wij onder Huishoudkunde verstaan - te wijzen op een eenvoudig engelsch schoolboekje, uit de bekende Collins' school series, waarvan de meestal even degelijke als eenvoudige werkjes in Engeland gebruikt worden in scholen, die met onze scholen van meer uitgebreid lager onderwijs en middelbare en latijnsche scholen veel overeenkomst hebben. Het werkje heet: Lessons in Domestic economy for elder girls, by Juseph Hassell, Associate of King's College.

Achtereenvolgens spreekt de schrijver daarin, op de meest verstaanbare en tevens op zeer degelijke wijze: over de oorzaken vain den groei en de geheele ontwikkeling van het menschelijk lichaam, van af het kind in de wieg, tot aan het meisje, dat nu in de school Huishoudkunde komt leeren. Dat lichaam wordt voorgesteld als een machine en er wordt gewezen op de behoeften en den aard der verschillende grondstoffen, die dit levend werktuig noodig heeft. De constructie der machine wordt aandachtig nagegaan, men wijst er de hefboomen, scharnieren, verbindingen, pompen en de 
drijfkracht in aan, en komt zóó geleidelijk tot de hehandeling der verschillende deelen, beenderen, spieren, zenuwen, bloed, huid enz. Men gaat voort met den scheikundigen samenstel der beenderen te onderzoeken en wijst dien o. a. aan door proefnemingen door afkoking, verbranding en behandeling met chloorwaterstofzuur. Hetzelfde geschiedt, doch langs andere wegen, met de spieren en het bloed, waarna men, diezelfde beenderen, het vleesch, het bloed enz. als voedingsmiddelen beschouwende en dezelfde bestanddeelen ook in het overige plantaardige en dierlijke voedsel aanwijzende, de voedingsmiddelen in de bekende vier klassen rangschikt, namelijk eiwitrijke of bloedvormers, vetten, zetmeelrijke of ademhalingsmiddelen, en minerale. Dan komt de vraag in behandeling: hoe het voedsel in bloed overgaat en wordt het scheikundige gedeelte zoowel van het ademhalings- als van het verteringsproces met de bloedsomloop in korte, duidelijke trekken omschreven. Hierna gaat men de verschillende dierlijke, plantaardige en minerale voedingsmiddelen nauwkeuriger beschouwen; het eerst, rund-, schapen-, varkens- en kalfvleesch, hun scheikundigen samenstel, voedingswaarde, verteerbaarheid enz., terwijl men eindigt met de berekening van den werkelijken prijs in geld, dien vleesch als voedingsmiddel waard is. Daarop volgt de studie der melk; haar scheikundige samenstel wordt met proeven aangewezen; in hare kaasstof duidt men dezelfde voedende elementen aan, die in het vleesch voorkomen enz. Aan de ten onrechte zoo lang geminachte karnemelk wordt hare werkelijke voedingswaarde toegekend. Op dezelfde wijze worden uitvoerig boter en kaas, daarna eieren en ten laatste ook visch behandeld, om eindelijk over te gaan tot de studie van het plantaardige voedsel. Microscopisch en scheikundig wordt de graankorrel onderzocht, de voedingswaarde der verschillende meelsoorten aangeduid en daarna uitvoerig het geheele proces der broodbereiding besproken. In gelijken geest worden haver, gerst, maïs, rijst, arrow-root, sago en tapioca en wat uit al die stoffen vervaardigd wordt, alsmede de wijze hoe dit geschiedt, behandeld. Eene afzonderlijke les wordt aan de studie van de suiker, eene andere an de zoo belangrijke peulvruchten, en nog eene andere aan die der zoogenaamde versehe groenten en vruchten gewijd. Na dan nog over het zout, zijn samenstel en zijne rol in de voeding te hebben gesproken en de verschillende voedingsmiddelen naar hunne percentsgevijze verhouding als bloedvormers en ademhalingsmiddelen te hebben gerangschikt, wordt de vraag behandeld, hoe dikwerf, 
hoe veel en hoe men eten moet. Er volgen dan gezondheidslevensregelen met betrekking tot het gebruiken van spijzen en dranken en van lieverlede is men, na de spijzen en dranken nauwkeurig te hebben leeren kennen, genaderd tot de bereiding der spijzen. Hier begint de eigenlijke wetenschappelijke kookkunst, en nauwkeurig en degelijk worden het hoe en waarom der bereiding van spijzen door koken, stoven, smoren, braden, bakken, roosten enz., behandeld, gevolgd door eenige korte, maar nuttige wenken voor den inkoop van spijzen en dranken. Daarna wordt de warmte en hare anwending in de huishouding besproken. De versehillende brandstoffen en verbrandingstoestellen (kachels enz.) worden met de meeste nauwlettendheid onderzocht. In het derde gedeelte van het werkje worden, op dezelfde bondige en leerrijke wijze, de dranken behandeld; de grondstoffen waaruit zij zijn bereid worden botanisch, scheikundig en technologisch besproken, en ten slotte worden nu ook wenken gegeven wat en hoeveel men drinken moet. Dit derde gedeelte sluit met eene verhandeling over de verschillende specerijen, kruidnagels, nootmuskaat, foelie, kaneel, jamaïca- en gewone peper, gember, mosterd enz. Het vierde gedeelte handelt over de lucht die wij inademen, haar samenstel, hare eigenschappen, dat alles inzonderheid strekkende om de hooge belangrijkheid van zuivere lucht te doen uitkomen. Volgen daarna regels voor luchtverversching en aanwijzing van de gewone oorzaken van luchtbederf. Dan komt eene verhandeling over de reiniging van ons lichaam; het physiologisch en microscopisch onderzoek van de huid; het nut van het veranderen der onderkleeding en eindelijk de wousch, waarvan elke verrichting b. v. het bleeken, stijven, strijken enz., wetenschappelijk wordt verklaard, terwijl de samenstel, de vervaardiging en de werking van zeep, soda en andere waschmiddelen uitvoerig wordt behandeld. Op dezelfde wijze spreekt men nu over de reiniging van de woning, de wijze hoe de verschillende vertrekken, meubelen enz. schoon gemaakt en onderhouden moeten worden. In het vijfde gedeelte bespreekt de schrijver de kleederen, hunne vervaardiging, de grondstoffen, die daartoe dienen, de wijze van fabriekmatige on gewone bewerking; de wetenschappelijk te verdedigen beste kleeding enz. In het zesde gedeelte worden de eerste beginselen der Huishoudbestuurkunde besproken, de verdeeling van den arbeid in het gezin, de boekhouding, het op- en vaststellen der jaarlijksche begrooting, de besparing van geld, spaarbanken, levensverzekeringen, zieken- en hegrafenisfondsen, - effecten enz. Het boekje 
eindigt met eene korte, doch zaakrijke verhandeling over de meest voorkomende kleine ongesteldheden, kinderziekten, kleinere of grootere ongevallen die dadelijke hulp behoeven en eindelijk de verpleging van zuigelingen en zeer jonge kinderen.

Zoo als men ziet, worden in dit kleine schoolboek verschillende wetenschappen te baat genomen ter bewerking eener leerstof, die de schrijver Huishoudkunde noemt. Hassell blijkt een man van veelzijdige kennis, geen zoogenaamde specialiteit in één enkel leervak. Lieden van zijne soort zijn voorzeker de beste schrijvers over dit onderwerp, daar zij met hun ruimeren en. algemeenen blik de zaak geheel en al overzien, en niet met hun liefhebberijvak daarop een loodzware pressie uitoefenen. Intusschen worden zulke lieden met den dag schaarscher, en om deze en nog andere redenen geloof ook ik derhalve, dat de verschillende leervakken, waaruit Huishoudkunde bestaat, in twee, drie, hoogstens vier groepen, moeten gesplitst worden, en het doceeren van elk van deze groepen, zoomede de leiding der aan elke groep verbonden practische oefeningen aan eene bekwame leerares moet toevertrouwd worden. Ik zeg: leerares, want, mijns inziens, behooren leeraren bij het middelbaar onderwijs voor meisjes niet dan in onoverkomelijke noodzakelijkheid daarbij gebezigd te worden. $\left({ }^{*}\right)$

Uit vrees van misbruik te zullen maken van de ruimte, die voor opstellen als de mijne in dit tijdschrift kan opengesteld worden, zal ik ditmaal de vraag niet behandelen, hoe, mijns bedunkens, de theorie der Huishoudkunde an meisjesscholen zou moeten geleeraard worden. Wellicht vraag ik daarvoor aan de Redactie nog een of meermalen een plaatsje. De methode van Hassell intussehen komt mij niet als eene daartoe geschikte voor. Veel wordt door hem onbesproken gelaten, dat bepaald bij dat onderricht niet mag ontbreken, terwijl menig onderwerp van bepaald huishoudkundig belang, veel te oppervlakkig wordt behandeld.

Ik deelde, aan 't eind van dit mijn opstel, een kort verslag van Hassell's werkje alleen mede, ten einde hen, die haar niet kennen, een blik in de Huishoudkunde te laten slaan.

Multapatior.

(*) $W_{i j}$ deelen dit gevoelen niet, en meenen integendeel dat voor het middelbaar onderwijs voor meiajes, het doceeren door leeraars regel behoort te zijn, met nitzondering natınrlijk voor de meer speciaal-vrouwelijke vakken.

REv. 
Correspondentie. (Inqezonden.) Professor Luigi Bodio, directeur der statistiek te Rome, bad de welwillendheid mij dezer dagen te zenden een exempluar van zijn "Populazione Movimento" dello stato civile. Anno 1875. Introduzione.

Jit werk in 1877 te Rome uitgegeven op last en roor rekening van het Italiaansch ministerie van landbouw, nijverbeid en handel (afdeeling statistiek) verdient de belangstellende sandacht van de statistici in Nederland. Ofschoon slechts inleiding, bevat dit werk 167 pagina's groot octavo. Het eerste gedeelte is gewijd an de statistiek der huwelijken, stelselmatig en oordeelkundig geordend, aanvangende met 1863 en eindigende met 1875 .

Achtervolgens worden belandeld: Italie, Frankrijk, Engeland, Pruissen, Beijeren, Oostenrijk, Nederland en Zweden. De cijfers der huwelijken in die verschillende rijken worden vergeleken. Hiertoe vindt men in dit werk zeer belangwekkende vergelijkende staten. Wat Italie betreft worden ook de huwelijken per maand opgegeven (1874, 1875). Vervolgens wordt voor datzelfde rijk de verhouding der huwelijken op 12000 zielen aangegeven. De groeperingen zijn zoodanig dat uit de cijfers de meest gunstige gevolgtrekkingen voor de wetenschap der statistiek kunnen worden afgeleid. Dit geldt vooral de hoofdstakken: "Matrimone tra consanguinei" en "Istruzione elementare degli sposi."

Hierna worden de geboorten - wettige en onwettige - behandeld (1865-1875). Darop volgen vitgebreide statistieken betrekkelijk de vruchtbarheid der bevolking in Italie, gevolgd van vergelijking der verhouding van de geboorten in reeds gemelde verschillende rijken. Voor Italie worden ook de geboorten per maand opgegeven. Nu volgen statistieken betreffende de doodgeborenen, voor de meer genoemde rijken, op 100 vrouwen. Het thans volgend gedeelte is gewijd aan bet overlijden.

Bet blijkt bieruit dat ten jare 1875 in het geheele Italiasnsche rijk 843,161 personen overleden zijn; zijnde 431.756 mannen en 411.405 vrouwea, zoodat de verhouding was als 105 tot 100 .

De sterfte was, wat plaatselijke gesteldheid betreft aldus rerdeeld:

$\begin{array}{lcccc} & & \text { Totaal. } & \text { Manneu. } & \text { Vrouwen. } \\ \text { Steden . . . . . } & 284029 & 147783 & 136246 \\ \text { Platte land . . . . } & \frac{559132}{843161} & & \frac{283973}{431756} & \frac{275159}{411405}\end{array}$

Alsnu wordt de algemeene sterfte der bevolking in Italie opgegeren, t.erwijl wijders vergelijkende tabellen de verhouding anwijzen der sterfte op 100 geborenen. In Veuefie was de minimum verhouding: 72 slerfte op 100 geburemen. 
Een tiende deel overleed alvorens eene maand bereikt te hebbeu.

" vierde " " " jaar " "

Het tweede jaar leverde een groot contingent voor de sterfte nl. 10,23 van de 100 overledenen in bet geheel.

$\mathrm{Na}$ het tweede jaur werd de verbouding voor het in leven blijven op eens, plotseling als het ware, veel gunstiger.

$\mathrm{Nu}$ volgt eene statistiek voor het geheele Italiannsch rijk (afzonderlijk voor gebuwden, ongehuwden, weduwen en weduwnars) en wel: van de geboorle tot ééne maand, van ééne maand tot 3 muanden, van 3 tot 6 , van 6 tot 9 , van 9 tot 12 ; van de geboorte tot 1 juar, van 1 jaxr tot 2 juren; vau 2 tot 3 , van 3 tot 4 , van 4 tot 5 , van 5 tot 10 en 200 vervolgens voor tijdvakken van 5 jaren; tot 95 en dan van 95 tot 99 , eindelijk honderdjarigen en onderdom onbekend. Voor de verschillende geuoemde rijken wordt nu de verhouding opgegeven per 100 . Hier treedt de zamensteller in wetenschappelijke beschouwingen in betrekking tot de berekening der sterfte volgens de methode van Halley, eene methode, die bij stellig "onvoldoende" acht, en warroor hij dan ook gronden aanvoert. Bij wijst an hoe hij zijne verhoulingen berekend heeft, zonde: dat de lezer met formules wordt bezig gehouden of vermoeid. In verband met het voorgande vindis men nu statistische gegevens omtrent de foeneming der bevolking ook in andere, behalve de reeds genoemde belangrijke Staten van Europa. Voor Nederland wordt als meetkunstige middenevenredige der jaarlijksche toeneming opgegeven, voor bet tijdvak van 1795 tot 18610,71

$$
\text { " " } " 1860,1874 \quad 0,87
$$

De kunäige schrijver treedt $n u$ in bijzonderbeden omtrent gewelddadigen dood. In 1875 werden in het geheel Italiaunsch rijk $9459 \mathrm{gr}$ vallen van zoodanigen ard geregistreerd; aldus verdeeld : 7163 mannen en 2296 vrouwen.

Wat in het bijzonder accidenteelen dood betreft worden ook belang* rijke statistische gegerens verstrekt.

Duidelijk blijkt hier dat ook in Italie let misbruik van den sterken drank veel offers eischt, en wel: in 1874: 33 mannen, en in 1875: 43 mannen en 3 vrouwen.

Wat de zelfmoord voor de beide geslachten angaut, worden mede belangrijke gegevens verstrekt, niet alleen wat hetreft de wijze maur ouk de vermoedelijke oorzaken.

M. Hentiquez Pimenesel. 